\title{
SIGHTINGS OF ALBINO FLICKER AT PIKE LAKE, SASKATCHEWAN
}

\section{AUSTIN FORSYTH, 197-325-5TH Avenue, Saskatoon, Saskatchewan. S7K 2P7}

For a number of people who live near the west shore of Pike Lake, Saskatchewan, 17 August 1987 was a memorable day, because it produced multiple sightings of a white woodpecker which appears to have been an albino variant of the Yellow-shafted Flicker.

Ethel and I were sitting on the deck of our cabin, enjoying the morning sun and the worm-pulling antics of robins on the short grass between us and the lake, when a strange white bird arrived with a flock of seven or eight Yellow-shafted Flickers who started to forage hungrily in the sod.
Although the white one seemed slightly larger than its companions, in feeding habits and profile there was no noticeable difference.

Our nearest point of observation was about $3 \mathrm{~m}$., at which distance we had an excellent view of the plumage except for its underparts and extended wings. The only pigmentation noted was a red patch at the nape of the neck and a faint yellowish staining along the lower back. We could not tell anything about the color of its eyes, but because it was the first of the flock to move out of the bright sun

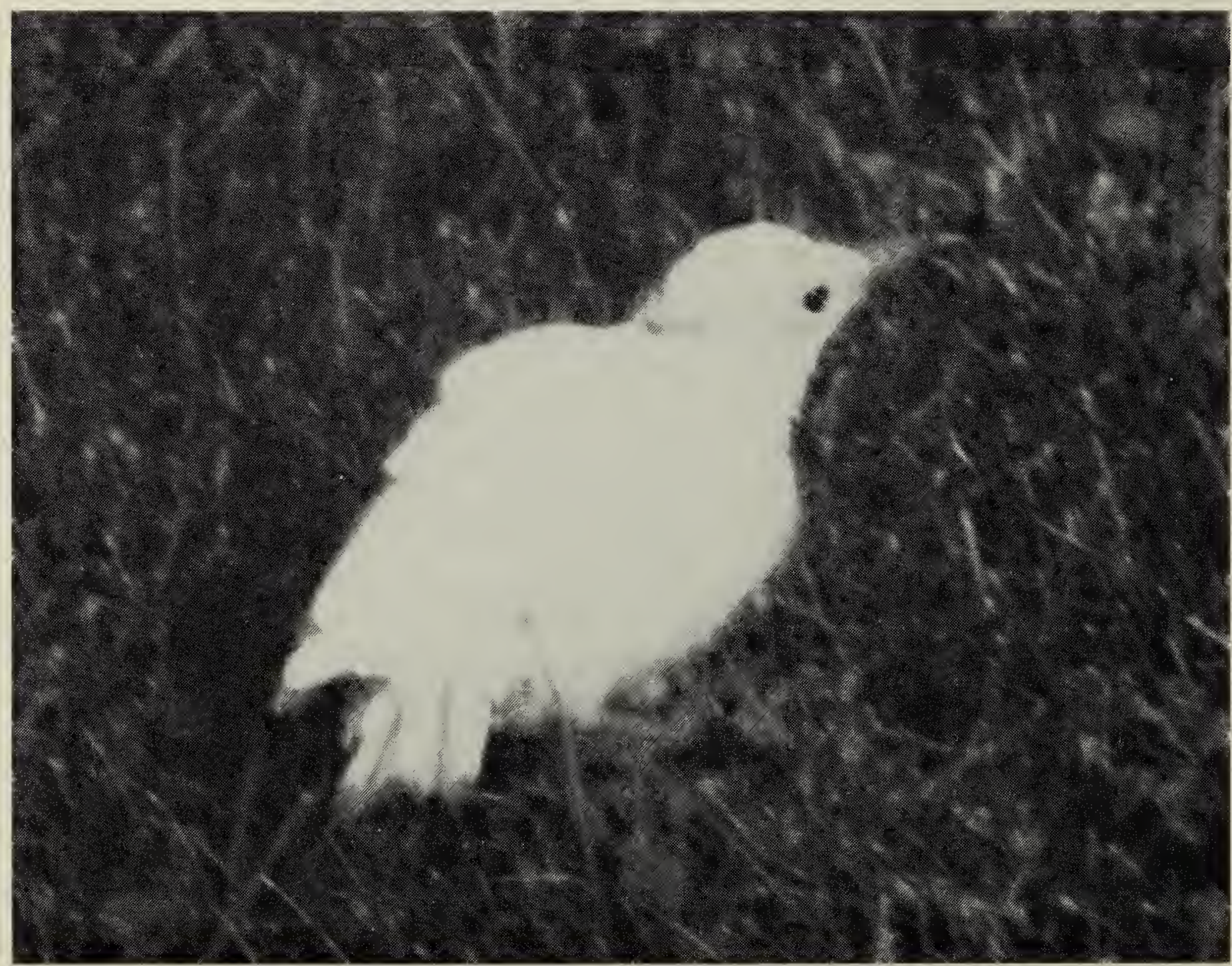


into the shade of the underbrush, we speculated on a deficiency of intra-ocular pigment.

The decision that the bird was a variant of the Yellow-shafted subspecies was based on its red nape marking, the company it kept, and the absence of red "moustache" streaks which could be expected on a male of the Red-shafted subspecies if the genetic determinant for red were unaffected. The red and yellow colors show on Isabel Maguire's photographs which also show a pale bill.
We saw no sign of avoidance or rejection of the albino by other members of the flicker flock, but other observers felt that it was ostracized by normal birds while feeding.

Among those who played host to this unusual bird were Stan Magill, Isabel and Harold Maguire, Ferne and Hub Braithwaite, Audrey Brandt and Sandy Frischholz ... each of whom sighted it on grounds separated one from the other by only a few hundred metres.

Thus an addiction to White Bird Watching has swept into our community!

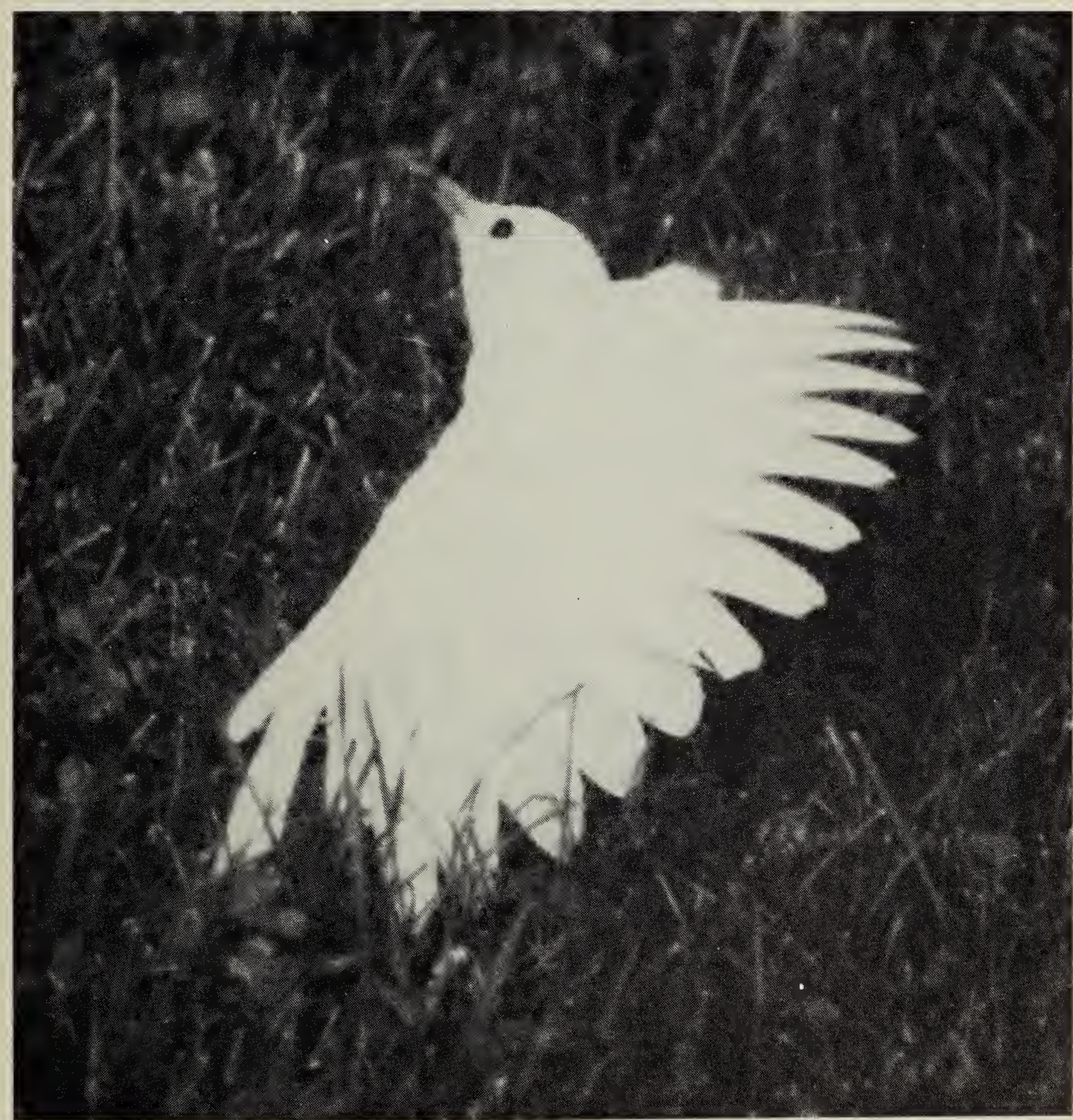

